\title{
Penggunaan Media Peta Konsep untuk Meningkatkan Hasil Belajar pada Mata Pelajaran Pendidikan Agama Islam di Kelas V SDN 007 Kunto Darussalam Tahun 2017
}

\author{
Purnamawati \\ Sekolah Dasar Negeri 007 Kunto Darussalam, Dinas Pendidikan Rokan Hulu Riau, Indonesia \\ e-mail: purnamawatidarussalam@gmail.com
}

\begin{abstract}
This Classroom Action Research was conducted because the learning outcomes of Islamic Education of the fourth grade students of Kunto Darussalam State Elementary School 007 were still relatively low. To overcome this problem is with the Use of Media Concept Maps. The purpose of this study was to improve the learning outcomes of Islamic Education of fourth grade students of Kunto Darussalam 007 Elementary School with the Use of Media Concept Maps. The method of this research is Classroom Action Research (CAR) carried out in two cycles. Each cycle consists of two meetings and four stages, namely planning, implementation, observation, and reflection. This research was conducted in November 2017. The subjects in this study were teachers and fifth grade students in the 2016-2017 school year with a total of 24 students divided into 13 men and 11 women. Data collection techniques used in this study were observation, testing, and documentation techniques. Based on the results of the study it can be concluded that before the treatment there were only 11 or $46 \%$ of the students reached the completion standard. While in the first cycle it increased to 16 students or 66\%. In cycle II it increased again to reach 22 students or with a percentage of $92 \%$. So it can be concluded that the Use of Media Concept Maps can improve the learning outcomes of Islamic Education of fourth grade students of Kunto Darussalam State Elementary School 007.
\end{abstract}

Keywords: Media Concept Map and Learning Outcomes of Islamic Education.

\section{PENDAHULUAN}

Pendidikan merupakan suatu proses yang berfungsi membimbing siswa dalam kehidupan sesuai dengan tugas-tugas perkembangan yang harus dijalani oleh anak didik. Tugas dari perkembangan itu mencakup aspek kebutuhan hidup baik sebagai individu maupun sebagai anggota masyarakat yang berlangsung secara bertahap. Bila ditinjau secara luas manusia yang hidup dan berkembang adalah munusia yang selalu berubah dan perubahan itulah dinamakan hasil belajar.

Dalam proses pembelajaran salah satu faktor eksternal yang mempengaruhi hasil belajar siswa adalah cara mengajar/metode guru dalam menyampaikan materi pelajaran kepada siswa. Untuk itu kemampuan guru sangat dituntut dalam mengelola kelas agar suasana belajar siswa selalu aktif dan produktif melalui strategi dan metode mengajar yang direncanakan.

Berdasarkan hasil pengamatan, pembelajaran PAI di sekolah dasar belum sesuai dengan hakikat PAI dan tuntutan kurikulum sekolah dasar. Sebagaimana pengamatan yang dilakukan, di kelas V SDN 007 Kunto Darussalam guru mengajarkan PAI dengan metode ceramah, tanya jawab secara monoton pada semua materi, hal ini berdampak pada hasil belajar murid yang rendah. 
Berdasarkan hasil survey di kelas V SDN 007 Kunto Darussalam ditemui gejalagejala atau fenomena pada pelajaran PAI sebagai berikut: (1) dari nilai ketuntasan yang ditetapkan sekolah yaitu 70, maka pada kelas V dari jumlah siswa sebanyak 24 orang, terdapat 11 orang siswa saja yang mendapatkan nilai hasil belajar yang mencapai Kriteria Ketuntasan Minimal atau sebesar 44\%, sedangkan sisanya 13 orang atau 56\% masih diberikan nilai tambahan dari guru. (2) iswa terkesan sulit memahami materi yang disampaikan oleh guru di kelas, hal ini terlihat bahwa lebih dari 70\% siswa memiliki nilai tugas yang rendah. (2) dalam proses pembelajaran, siswa jarang menjawab pertanyaan yang diberikan oleh gurunya apalagi bertanya. Hal tersebut terlihat ketika sesi Tanya jawab, dimana dari 24 orang siswa hanya 11 orang saja atau sebesar 48\% yang bias menjawab dan itupun hanya siswa tertentu saja, sedangkan sisanya yaitu 13 orang atau $52 \%$ lebih banyak diam ketika ditanya guru, atau disuruh bertanya.

Dari fenomena-fenomena atau gejala-gejala tersebut di atas, terlihat bahwa hasil belajar siswa belum optimal, khususnya pada mata pelajaran PAI. Sebenarnya banyak upaya yang telah dilakukan oleh guru, untuk memperbaiki atau mendorong siswa untuk lebih giat belajar. Selain membuat silabus dan rencana pelaksanaan pembelajaran, guru juga memberikan tugas kelompok, dengan maksud agar siswa mau belajar di rumah bersama teman kelompoknya. Selain itu, berbagai upaya guru telah dilaksanakan untuk mengajarkan pembelajaran PAI di sekolah dasar, untuk meningkatkan hasil belajar murid pada materi pelajaran PAI antara lain dengan memberikan pelajaran tambahan, mendiskusikan pelajaran yang akan diberikan dan guru memerintahkan murid untuk membaca buku-buku yang sesuai dengan materi pelajaran. Namun semua upaya yang guru lakukan tersebut hasilnya belum sesuai dengan yang diharapkan, terbukti masih rendahnya nilai atau hasil belajar siswa. Oleh karenanya, pada penelitian ini penulis bermaksud melaksanakan strategi pembelajaran yang baru dan belum pernah dilaksanakan di SDN 007 Kunto Darussalam yaitu penggunaan media peta konsep.

Hisyam Zaini dkk dalam bukunya yang berjudul "Strategi Pembelajaran Aktif" menyatakan bahwa Peta Konsep adalah meminta siswa mensintesis atau membuat suatu gambar atau diagram tentang konsep-konsep utama yang saling berhubungan, yaitu ditandai dengan garis panah ditulis level yang membunyikan bentuk hubungan antar konsep-konsep utama itu. Selanjutnya, Abuddin Nata menjelaskan bahwa media Peta Konsep disebut juga dengan strategi pemilihan cepat, yang mempunyai arti teknik pemilihan dan penentuan prioritas dari beberpa alternatif kemungkinan program yang telah disusun dan program itu akan dilaksanakan. Teknik ini digunakan pula untuk memilih masalah-masalah yang dihadapi dan harus segera dipecahkan. Cara pemilihan dilakukan dengan cepat, sesuai dengan nama teknik tersebut.

Mencermati uraian tentang media Peta Konsep di atas, maka penulis tertarik ingin melakukan suatu penelitian tindakan sebagai upaya perbaikan terhadap pembelajaran dengan judul: "Penggunaan Media Peta Konsep Untuk Meningkatkan hasil Belajar pada mata pelajaran Pendidikan Agama Islam di Kelas V Sekolah Dasar Negeri 007 Kunto Darussalam tahun 2017"

\section{METODOLOGI}

Penelitian ini menggunakan rancangan penelitian tindakan kelas (Classrom based action research). Peneliti dalam penelitian ini sebagai pelaksana penelitian, pengumpul data, penganalisis data dan pelaporan hasil penelitian melalui tahap perencanaan, pelaksanaan, 
pengamatan, dan refleksi. Untuk mengumpulkan data di lapangan penulis menggunakan teknik observasi, tes tertulis, dan dokumentasi.

Teknik analisis data terhadap aktivitas guru dan siswa dilaksanakan menggunakan teknik persentase. Setelah data terkumpul melalui observasi, data tersebut diolah dengan menggunakan rumus persentase, yaitu sebagai berikut:

$$
P=\frac{F}{N} x 100 \%
$$

Keterangan :

$\mathrm{P} \quad=$ Angka Persentase aktivitas guru

$\mathrm{F} \quad=$ Frekuensi aktivitas guru

$\mathrm{N} \quad=$ Jumlah indikator

100\% = Bilangan tetap (Sudijono, 2004:43)

Dalam menentukan kriteria penilaian tentang hasil observasi, maka dilakukan pengelompokkan atas 5 kriteria sebagai berikut:

Tabel 1. Interval Kategori Aktivitas Guru dan Siswa

\begin{tabular}{cll}
\hline NO & Interval & Kategori \\
\hline 1 & $90 \mathrm{sd} \mathrm{100}$ & $=$ Sangat Baik \\
2 & $70 \mathrm{sd} 89$ & $=$ Baik \\
3 & $50 \mathrm{sd} 69$ & $=$ Sedang \\
4 & $30 \mathrm{sd} \mathrm{49}$ & $=$ Kurang \\
5 & $10 \mathrm{sd} 29$ & $=$ Sangat Kurang \\
\hline
\end{tabular}

Hasil belajar adalah nilai yang diperoleh siswa selama mengikuti pembelajaran dan diukur dengan melakukan tes tertulis. Untuk mencari hasil belajar siswa dapat digunakan rumus berikut:

$$
\text { HA }=\frac{\text { Skor maksimal }}{\text { Jumlah soal }} x \text { Jawaban yangbenar }
$$

Rentang nilai untuk tes sebagai berikut:

Tabel 2. Kategori Hasil Belajar

\begin{tabular}{lll}
\hline No & Interval (\%) & Kategori \\
\hline 1. & $86-100$ & Baik Sekali \\
2. & $71-85$ & Baik \\
3. & $56-70$ & Cukup \\
4 & $41-55$ & Kurang \\
5. & $<40$ & Sangat Kurang \\
\hline
\end{tabular}

\section{HASIL DAN PEMBAHASAN}

Hasil

Siklus I

\section{Hasil Pengamatan Aktivitas Guru Siklus I}


Pertemuan pertama dilaksanakan pada hari Kamis tanggal 9 November 2017, yaitu pada jam pelajaran ketiga dan keempat. Pertemuan kedua dilaksanakan pada hari Kamis tanggal 16 November 2017, yaitu pada jam pelajaran ketiga dan keempat. Dalam pelaksanaan pembelajaran melibatkan seluruh siswa kelas V. Pelaksanaan pembelajaran dilakukan berdasarkan Rencana Pelaksanaan Pembelajaran (RPP) yang telah dipersiapkan dan berpedoman pada silabus, dan kurikulum dengan mengikuti langkah media Peta Konsep.

Pada pertemuan 1 diperoleh persentase ketercapaian guru dalam melaksanakan pembelajaran sebesar $60 \%$ atau kategori sedang. pertemuan 2 sebesar $75 \%$ pada kategori baik.

Tabel 3. Hasil Pengamatan Aktivitas Guru Pada Siklus I

\begin{tabular}{lllll}
\hline No & Siklus & Pertemuan & Aktivitas Guru (\%) & Kategori \\
\hline 1 & I & I (Pertama) & $60 \%$ & Sedang \\
& & II (Kedua) & $75 \%$ & Baik \\
\hline Rata-rata & & $63,5 \%$ & Sedang \\
\hline
\end{tabular}

\section{Hasil Pengamatan Aktivitas Siswa Siklus I}

Aktivitas siswa secara klasikal atau secara keseluruhan pada siklus I pertemuan 1 sebesar 64\% dengan kategori sedang, pertemuan 2 sebesar 73\% dengan kategori baik.

Tabel 4. Hasil Pengamatan Aktivitas Siswa Siklus I

\begin{tabular}{lllll}
\hline No & Siklus & Pertemuan & Aktivitas Guru (\%) & Kategori \\
\hline 1 & I & I (Pertama) & $64 \%$ & Sedang \\
& II (Kedua) & $73 \%$ & Baik \\
\hline Rata-rata & & $67 \%$ & Sangat \\
\hline
\end{tabular}

\section{Hasil Belajar Siswa pada siklus I}

Hasil belajar siswa pada siklus I secara klasikal diperoleh jumlah rata-rata 75 berada pada interval $70-89$ dengan kategori baik. Siswa yang tuntas sebanyak 16 orang siswa atau $66 \%$ dan sisanya belum tuntas. Dapat dilihat pada tabel 5 berikut.

Tabel 5. Hasil Belajar Siswa Pada Siklus I

\begin{tabular}{clll}
\hline No & Siswa & Nilai UH 2 & Ketuntasan \\
\hline 1 & Andra Fekdiani & 85 & T \\
2 & Anggi Candra & 65 & TT \\
3 & Asnidar Epolia & 75 & T \\
4 & Cinta Seruwahni & 70 & TT \\
5 & Enda Erizal & 65 & TT \\
6 & Erwindo & 80 & T \\
7 & Ismalia Amelta & 90 & T \\
8 & Lestia & 65 & TT \\
9 & M. Hafiz Aulia & 90 & T \\
10 & Mia Astusi & 65 & TT \\
11 & Muhammad Riski & 70 & T \\
12 & Mustika Sukma & 70 & T \\
13 & Nurul Karmila & 65 & TT \\
14 & Pahri Rozi & 100 & T \\
15 & Putrilia Agustin & 75 & T \\
\hline
\end{tabular}




\begin{tabular}{llll}
\hline 16 & Rio & 80 & $\mathrm{~T}$ \\
17 & Rio Pratama & 70 & $\mathrm{~T}$ \\
18 & Salma Khairani & 65 & $\mathrm{TT}$ \\
19 & Santi Lastar & 90 & $\mathrm{~T}$ \\
20 & Sherly Ristiani & 65 & $\mathrm{TT}$ \\
21 & Syahri Farel & 70 & $\mathrm{~T}$ \\
22 & Tika Wulandari & 70 & $\mathrm{~T}$ \\
23 & Yudi Pratama & 80 & $\mathrm{~T}$ \\
24 & Zulham & 80 & $\mathrm{~T}$ \\
\hline Jumlah & 1800 & 16 \\
\hline
\end{tabular}

\section{Refleksi siklus I}

Refleksi pada siklus pertama diperoleh berdasarkan hasil analisis data untuk tiap-tiap langkah pelaksanaan tindakan yang akan dideskripsikan peneliti pada tahap ini. Selanjutnya didiskusikan dengan observer, yang berperan sebagai observer yaitu teman sejawat. Memperhatikan deskripsi proses pembelajaran yang dikemukakan dan melihat hasil belajar siswa pada pelajaran PAI, maka berdasarkan hasil pembahasan peneliti dan pengamat terhadap perbaikan pembelajaran pada siklus pertama terdapat beberapa kelemahan pembelajaran diantaranya:

- Pengelolaan pembelajaran oleh peneliti telah sesuai dengan tahapan yang dimuat dalam RPP, namun penggunaan Media Peta Konsep dalam proses pembelajaran masih mengalami beberapa kelemahan khususnya adalah:

a. Guru memintalah kembali peserta didik untuk menuliskan konsep-konsep utama

b. Guru meminta peserta didik untuk mencoba beberapa kali membuat gambar yang saling berhubungan antar konsep

c. Guru memastikan peserta didik membuat garis penghubung antar konsep

- Partisipasi siswa yang diobservasi dalam lembar observasi aktivitas siswa pada dasarnya sudah dalam kategori baik, aspek yang menjadi perhatian adalah pada aktivitas nomor 6 yaitu membuat garis penghubung antar konsep, dimana siswa yang tergolong aktif yaitu baru 50\%, kemudian pada aktivitas nomor 7 yaitu menulis satu kata atau level di atas garis penghubung, siswa yang tergolong aktif hanya $33 \%$.

- Sedangkan untuk hasil belajar siswa masih pada tingkat yang cukup, kemampuan siswa menangkap pelajaran dalam belajar tidak terlepas dari aktivitas guru. Hasil belajar siswa diprediksi meningkat seiring dengan adanya kepiawaian guru dalam membawakan materi pelajaran.

\section{Siklus II}

\section{Hasil Pengamatan Aktivitas Guru Siklus II}

Siklus II pertemuan 1 sebesar 85\% dengan kategori "baik" dan pertemuan 2 sebesar 90\% dengan kategori "Sangat Baik" berdasarkan hasil tersebut terjadi peningkatan dari siklus I ke siklus II.

Tabel 6. Hasil Pengamatan Aktivitas Guru Pada Siklus II

\begin{tabular}{lllll}
\hline No & Siklus & Pertemuan & Aktivitas Guru (\%) & Kategori \\
\hline 1 & I & I (Pertama) & $85 \%$ & Baik
\end{tabular}




\begin{tabular}{|c|c|c|}
\hline & $90 \%$ & Sangat Baik \\
\hline Rata-rata & $88 \%$ & Sangat Baik \\
\hline
\end{tabular}

\section{Hasil Pengamatan Aktivitas Siswa Siklus II}

Siklus II pertemuan 1 sebesar $80 \%$ dengan kategori "Baik" dan pada pertemuan 2 sebesar 91\% dengan kategori "Sangat Baik".

Tabel 7. Hasil Pengamatan Aktivitas Guru Pada Siklus I

\begin{tabular}{rrrrr}
\hline No & Siklus & Pertemuan & Aktivitas Guru (\%) & Kategori \\
\hline 1 & I & I (Pertama) & $80 \%$ & Baik \\
& II (Kedua) & $91 \%$ & Sangat Baik \\
\hline \multicolumn{5}{r}{ Rata-rata } \\
\hline
\end{tabular}

\section{Hasil Belajar Siswa pada siklus II}

Hasil belajar siswa pada siklus II secara klasikal diperoleh jumlah rata-rata 78,77 berada pada interval $70-89$ dengan kategori baik. Siswa yang tuntas sebanyak 22 orang siswa atau $92 \%$ dan sisanya belum tuntas.

Tabel 8. Hasil Belajar Siswa Pada Siklus I

\begin{tabular}{clll}
\hline No & Siswa & Nilai UH 2 & Ketuntasan \\
\hline 1 & Andra Fekdiani & 85 & $\mathrm{~T}$ \\
2 & Anggi Candra & 75 & $\mathrm{~T}$ \\
3 & Asnidar Epolia & 75 & $\mathrm{~T}$ \\
4 & Cinta Seruwahni & 70 & $\mathrm{~T}$ \\
5 & Enda Erizal & 90 & $\mathrm{~T}$ \\
6 & Erwindo & 80 & $\mathrm{~T}$ \\
7 & Ismalia Amelta & 90 & $\mathrm{~T}$ \\
8 & Lestia & 65 & $\mathrm{TT}$ \\
9 & M. Hafiz Aulia & 90 & $\mathrm{~T}$ \\
10 & Mia Astusi & 100 & $\mathrm{~T}$ \\
11 & Muhammad Riski & 70 & $\mathrm{~T}$ \\
12 & Mustika Sukma & 70 & $\mathrm{~T}$ \\
13 & Nurul Karmila & 70 & $\mathrm{~T}$ \\
14 & Pahri Rozi & 100 & $\mathrm{~T}$ \\
15 & Putrilia Agustin & 75 & $\mathrm{~T}$ \\
16 & Rio & 80 & $\mathrm{~T}$ \\
17 & Rio Pratama & $\mathrm{T}$ \\
18 & Salma Khairani & 70 & $\mathrm{TT}$ \\
19 & Santi Lastar & 65 & $\mathrm{~T}$ \\
20 & Sherly Ristiani & 90 & $\mathrm{~T}$ \\
21 & Syahri Farel & 80 & $\mathrm{~T}$ \\
22 & Tika Wulandari & $\mathrm{T}$ \\
23 & Yudi Pratama & 70 & $\mathrm{~T}$ \\
24 & Zulham & 70 & $\mathrm{~T}$ \\
\hline Jumlah & 80 & 22 \\
\hline
\end{tabular}

\section{Refleksi Siklus II}

Sebagian besar siswa sudah terlihat aktif walaupun belum semuanya, namun peneliti sudah merasa puas karena proses pembelajaran telah sesuai dengan apa yang peneliti 
rencanakan. Dari observasi yang dilakukan peneliti di siklus II dapat disimpulkan bahwa penerapan media Peta Konsep telah sesuai dengan yang direncanakan dan merupakan pembelajaran yang menyenangkan bagi siswa. Kemudian terdapat peningkatan hasil belajar siswa terhadap materi pelajaran. Sehingga hasil belajar siswa meningkat pada mata pelajaran PAI.

\section{Pembahasan}

\section{Hasil belajar}

Perbandingan antara hasil belajar pada Siklus I dan Siklus II secara jelas dapat dilihat pada Tabel berikut ini:

Tabel 9. Hasil Belajar Siswa

\begin{tabular}{lccc}
\hline & Data awal & Siklus I & Siklus II \\
\hline Rata-rata & 66,04 & 70,42 & 78,75 \\
Siswa tuntas & 11 & 15 & 22 \\
Persentase & $46 \%$ & $63 \%$ & $92 \%$ \\
Kategori & Kurang & Cukup & Baik sekali \\
\hline
\end{tabular}

Tabel di atas menjelaskan bahwa hasil belajar siswa sebelum tindakan dengan ratarata sebesar 66,04 dengan kategori kurang, kemudian pada siklus I mendapatkan rata-rata 70,42 (63\% siswa mendapatkan nilai KKM) dengan kategori cukup dan pada siklus II mendapatkan rata-rata kelas 78,75 (92\% siswa mendapatkan nilai KKM) dengan ketegori baik sekali.

\section{Aktivitas Guru}

Aktivitas guru selama kegiatan belajar mengajar dengan penerapan media Peta Konsep terjadi peningkatan secara positif. Pada siklus I setelah dilakukan observasi maka aktifitas guru dengan penerapan media Peta Konsep pada siklus I ini berada pada klasifikasi "Baik", dan aktifitas guru dengan penerapan media Peta Konsep pada siklus II ini berada pada klasifikasi "baik sekali" dengan persentase 90\%. Perbandingan aktivitas guru dapat dilihat dari tabel berikut:

Tabel 10. Aktivitas Guru

\begin{tabular}{cccc}
\hline No & Siklus & Rata-rata & Keterangan \\
\hline 1 & Siklus I pertemuan 1 & $60 \%$ & Sedang \\
2 & Siklus I pertemuan 2 & $75 \%$ & Baik \\
3 & Siklus II pertemuan 1 & $85 \%$ & Baik \\
4 & Siklus II pertemuan 2 & $90 \%$ & Sangat baik \\
\hline
\end{tabular}

Berdasarkan tabel di atas dapat diketahui bahwa aktivitas guru pada siklus I pertemuan 1 sebesar 60\% dengan kategori "sedang", pada pertemuan 2 sebesar 75\% dengan kategori "baik" dan siklus II pertemuan 1 sebesar 85\% dengan kategori "baik" dan pertemuan 2 sebesar 90\% dengan kategori "Sangat Baik" berdasarkan hasil tersebut terjadi peningkatan dari siklus I ke siklus II.

\section{Aktivitas Siswa}

Aktivitas siswa dalam pelaksanaan media Peta Konsep tersebut secara klasikal pada siklus I mencapai persentase $73 \%$. Setelah dibandingkan dengan standar klasifikasi yang 
telah ditetapkan di Bab III, maka aktifitas siswa dalam pembelajaran dengan media Peta Konsep pada siklus I ini berada pada klasifikasi "Baik". Aktivitas siswa dalam pelaksanaan media Peta Konsep tersebut secara klasikal pada siklus II mencapai persentase 91\%. Setelah dibandingkan dengan standar klasifikasi yang telah ditetapkan di Bab III, maka aktifitas siswa dalam pembelajaran dengan media Peta Konsep pada siklus II ini berada pada klasifikasi "Sangat Baik". Untuk lebih jelasnya dapat dilihat pada tabel berikut:

Tabel 11. Aktivitas Siswa

\begin{tabular}{cccc}
\hline No & Siklus & Rata-rata & Keterangan \\
\hline 1 & Siklus I pertemuan 1 & $64 \%$ & Sedang \\
2 & Siklus I pertemuan 2 & $73 \%$ & Baik \\
3 & Siklus II pertemuan 1 & $80 \%$ & Baik \\
4 & Siklus II pertemuan 2 & $91 \%$ & Sangat baik \\
\hline
\end{tabular}

Berdasarkan tabel di atas dapat diketahui bahwa aktivitas siswa siklus I pertemuan 1 sebesar 64\% dengan kategori "Sedang", pada pertemuan 2 sebesar 73\% dengan kategori "baik", siklus II pertemuan 1 sebesar 80\% dengan kategori "Baik" dan pada pertemuan 2 sebesar 91\% dengan kategori "Sangat Baik".

\section{KESIMPULAN DAN SARAN}

\section{Kesimpulan}

Hasil belajar siswa sebelum tindakan dengan rata-rata sebesar 66,04 dengan kategori kurang, kemudian pada siklus I mendapatkan rata-rata 70,42 (63\% siswa mendapatkan nilai KKM) dengan kategori cukup dan pada siklus II mendapatkan rata-rata kelas 78,75 (92\% siswa mendapatkan nilai KKM) dengan ketegori baik sekali.

Aktivitas guru pada siklus I pertemuan 1 sebesar 60\% dengan kategori "sedang", pada pertemuan 2 sebesar 75\% dengan kategori "baik" dan siklus II pertemuan 1 sebesar 85\% dengan kategori "baik" dan pertemuan 2 sebesar 90\% dengan kategori "Sangat Baik" berdasarkan hasil tersebut terjadi peningkatan dari siklus I ke siklus II.

Aktivitas siswa siklus I pertemuan 1 sebesar 64\% dengan kategori "Sedang", pada pertemuan 2 sebesar 73\% dengan kategori "baik", siklus II pertemuan 1 sebesar 80\% dengan kategori "Baik" dan pada pertemuan 2 sebesar 91\% dengan kategori "Sangat Baik".

\section{Saran}

Dalam upaya meningkatkan hasil belajar pendidikan agama islam, guru hendaknya menerapkan media peta konsep dalam pembelajaran pendidikan agama islam, kepada guru yang menggunakan media peta konsep agar melaksanakan langkah-langkah dalam penggunaan media peta konsep dalam proses belajar mengajar, hal ini untuk memntapkan lagi pemahaman siswa dalam konsep materi yang diajarkan.

\section{REFERENSI}

Agus Suprijono. 2009. Cooperative Learning : Teori dan Aplikasi PAIKEM. Yagyakarta: Pustaka Pelajar

Anas Sudijono. 2004. Pengantar Statistik Pendidikan. Jakarta: Raja Grafindo Persada

Bambang Warsita. 2008. Teknologi Pembelajaran Landasan \& Aplikasinya. Jakarta: Rineka Cipta 
Depag. 2005. al-Qur`an dan Terjemahnya. Bandung: Diponegoro

Dimyati dan Mudjiono. 2002. Belajar dan Pembelajaran. Jakarta: Rineka Cipta

Eva Susanti. 2011. Penerapan Model Pembalajaran Cooperative Tipe Quick on The Draw untuk Meningkatkan Motivasi Belajar Matematika Pada Materi Pecahan Siswa Kelas III MI Muhammadiyah Simpang Kubu. Pekanbaru: UIN Suska

Hamzah B. Uno. 2011. Model Pembelajaran, Jakarta. Bumi Aksara

Hisyam Zaini,dkk. 2007. Strategi Pembelajaran Aktif. CTSD, Edisi Revisi. Yogyakarta.

Nana Sudjana. 2009. Dasar-Dasar Proses Belajar Mengajar. Bandung: Sinar Baru Algesindo 